staff tended to by-pass us, while the consultants found it hard delegating responsibility to the senior registrar.

Nursing staff had particular difficulty in understanding our roles. The geriatric nurses tried to provide the psychiatrist with numerous psychiatric problems to manage, and the psychiatric nurses seemed to think that the swap was permanent and worked to involve the geriatric senior registrar in long-term planning. Physiotherapists and occupational therapists were very helpful in providing relevant information.

Disclosure to patients and carers of the details of the exchange was not discussed beforehand and we did not have an agreed policy. Some patients and carers were briefed but others, because of pressure of time or sensitivity issues, were not. In general, psychiatric and acute medical patients were not briefed. In more relaxed settings such as the Parkinson's disease clinic most patients were told and they often took the opportunity to discuss psychological problems. This occurred to a lesser extent in the geriatric out-patient clinics.

\section{Changes in practice}

There were some changes in practice after the swap. The psychiatrist continued to join in the geriatricians' ward round which was perceived as being extremely helpful by the nursing staff. Also, one of the old age psychiatry consultants has now changed his out-patient clinic to coincide with the geriatric out-patient clinic. The geriatrician feels he now gives increased priority to the symptoms of functional illness in his patients.

\section{Conclusions}

Some deficiencies in our exchange were highlighted and could be improved by the following recommendations.

(a) Extensive briefing of all medical and nonmedical staff should take place beforehand.

(b) Community experience in the geriatric job should be included.

(c) Details of the exchange should be disclosed to all patients and carers.

(d) Consultants should work towards increased delegation of responsibility.

The swap was, however, considered worthwhile by all involved. It may not deserve the title of a "direct exchange of posts" because only six sessions per week were used and there was not a straight swap of all senior registrar responsibilities. However, not only did the senior registrars gain, but there was also a general feeling that the exchange improved working relationships between the two departments.

\section{References}

Care of Elderly People with Mental Illness-Specialist Services and Medical Training (1989) A Joint Report of the Royal College of Physicians and the Royal College of Psychiatrists.

Reciprocal Training Schemes for Senior Registrars in Geriatric Medicine and Psychiatry of Old Age: A Discussion Document for the Joint Liaison Committee of the British Geriatrics Society and the Royal College of Psychiatrists (1990) BGS/RCPsych Liaison Committee.

\title{
The Transcultural Psychiatry (Special) Interest Group
}

The Transcultural Psychiatry (Special) Interest Group had its inaugural meeting at the Spring Quarterly Meeting in Dundee. Dr Parimala Moodley was elected as Chairperson. There will be a business meeting of this group during the Autumn Quarterly Meeting in Birmingham. All interested members are invited to attend. Members wishing to join the group are asked to send their names to Mrs Jean Wales at the College. 